\title{
Guideline concordance of bisphosphonates used for osteoporosis in a University Hospital, Thailand
}

\author{
Supalerk Anusathitwattana ${ }^{1}$, \\ Paphon Sa-ngasoongsong2, \\ Preecha Montakantikul ${ }^{1}$, \\ Nantaporn Lekpittaya ${ }^{3}$, \\ Busba Chindavijak ${ }^{1^{*}}$ \\ 1 Department of Pharmacy, Faculty of \\ Pharmacy, Mahidol University, Thailand \\ 2 Department of Orthopaedics, Faculty of \\ Medicine Ramathibodi hospital, \\ Mahidol University, Thailand \\ 3 Department of Clinical Pharmacy, Faculty \\ of Medicine Ramathibodi hospital, Mahidol \\ University, Thailand
}

*Corresponding author:

Busba Chindavijak

busba.chi@mahidol.ac.th
Keywords:

Bisphosphonates; Postmenopausal women; Osteoporosis; Osteoporotic fracture; Guideline concordance https://www.pharmacy.mahidol.ac.th/journal/ (c) Faculty of Pharmacy, Mahidol University (Thailand) 2021

\begin{abstract}
Bisphosphonates (BPs) are recommended as the first-line medication for osteoporosis mostly occurs in postmenopausal women and elderly men. This study was conducted to investigate (i) the percentage of prescribing BPs concordant to the Thai Osteoporosis Foundation 2010 (TOPF 2010) guideline, (ii) the cause of prescribing BPs non-concordant to the TOPF 2010 guideline, (iii) the prevalence of osteoporotic fracture, (iv) the factors related to osteoporotic fracture, and (v) the loss of medication cost determined from group of patients who received BPs non-concordant to the TOPF 2010 guideline. A nested casecontrol study was performed in all patients of Ramathibodi Hospital who consumed BPs during January and December 2012. One thousand patients were eventually recruited. Of these, 784 patients (78.4\%) received BPs concordant to the TOPF 2010 guideline and 216 patients $(21.6 \%)$ did not. The major cause of using BPs nonconcordant to the TOPF 2010 guideline was low bone mass without clinical risk factors (104 of 216 patients, 48.1\%). Prevalence of osteoporotic fractures was $2.9 \%$. Age (men $\geq 70$ years and women $\geq 65$ years) showed significant factor related to osteoporotic fracture with OR $1.0658(95 \% \mathrm{Cl}: 1.0248-1.1084 ; \mathrm{P}=0.0015)$. Loss of medication cost in the group of patients who received BPs nonconcordant to the TOPF 2010 guidelines was 4,261,488 THB/year. In conclusion, the concordance of BPs with TOPF 2010 guideline was 3.6 times higher than the non-concordance $(78.4 \%$ concordance and $21.6 \%$ non-concordance).
\end{abstract}

\section{INTRODUCTION}

Osteoporosis is a systemic skeletal disease which is characterized by a decreasing of bone mass and microarchitecture deterioration of bone tissue, leading to enhanced bone fragility and susceptibility to fracture ${ }^{1}$. Forty percent of women over age 50 years experienced osteoporotic fractures, whereas 13 percent of men aged over 50 years experienced ${ }^{2}$. Additionally, osteoporosis annually affects more than 8.9 million fractures throughout the world, resulting in an average osteoporotic fracture in every 3 seconds ${ }^{3,4}$. Prevalence of osteoporosis is increasing both in developed and developing countries. The Ministry of Public Health, Thailand, reported that osteoporosis was mostly found in postmenopausal women and older men ${ }^{5}$. It was found that Thailand had the number of older adults over 60 years increased from 6.8 percent in 1994 to fracture that causes of immobilization to the risk of another disease from hospitalization. International Osteoporosis Foundation (IOF) 
reported that the cost of fracture from osteoporosis in Europe was in the order of twenty-five thousand million euros per year. In Thailand, the problem was not reported. However, the cost of treatment in each patient with a 14.9 percent in $2014^{5}$. The symptom can be range from a bone hip fracture is approximately 120,000 baht per year ${ }^{5}$.

Therefore, it would be beneficial if sign or symptom of osteoporosis was early detected. At present, of bone mineral density (BMD) by the Dual Energy X-ray Absorptiometry (DXA) is used as standard methods for diagnosing osteoporosis according to the criteria of the World Health Organization (WHO). Using a value less than or equal to -2.5 standard deviation (SD) (T-score $\leq-2.5)$ from the mean of peak BMD in young female adult (reference population) for women and young male adult (reference population) for men to diagnose of osteoporosis. Furthermore, a value between -2.5 SD and -1 SD (T-score of $\geq-2.5$ but $<-1$ ), and a value above or equal to $-1 \mathrm{SD}$ ( $\mathrm{T}$ score of $\geq-1$ ) can be identified as osteopenia or low bone mass and normal bone mass, respectively ${ }^{6-7}$.

Goals of osteoporosis treatment are the prevention of fracture complication and the maintenance of good skeletal health. Important strategies include reducing the risk of fracture, increasing bone strength, reducing bone resorption, increasing bone formation, reducing pain from a bone fracture, encouraging body movement, reducing dependency and improving quality of life $^{8}$. The primary indication for postmenopausal women and men aged $\geq 50$ years should be considered for treatment if they have hip or vertebral fracture (clinically apparent or found on vertebral imaging or T-score $\leq-2.5$ at the femoral neck, total hip or lumbar spine $)^{9}$.

Bisphosphonates (BPs) are recommended as the first-line medication for treatment of osteoporosis. They provide antiresorptive effects by binding to the calcium hydroxyapatite crystal at sites of bone resorption, where the bone matrix is exposed. Their effects are inhibiting osteoclast activities and accelerating apoptosis of osteoclasts. BPs can increase BMD and decrease fracture risk ${ }^{10-11}$. Currently, BPs are used as the first-line therapy for osteoporosis in various hospitals in Thailand. The drugs are stated in Thai osteoporosis foundation (TOPF) 2010 guideline adopted by Thai Osteoporosis Foundation and is recommended to have drug holiday of 3-5 years after starting BPs ${ }^{12-14}$.
BPs while using for the treatment of osteoporosis, and osteoporotic fracture, but increased risk of atypical femur fracture (AFF) with prolonging therapy have been reported ${ }^{14-16}$. Chaiyong et al. reported that the use of alendronate and risedronate in postmenopausal women are not cost-effective for all groups of postmenopausal women except in the group of women aged $\geq 75$ years ${ }^{17}$.

As the high rate of BPs consumption in the past several years was observed in Ramathibodi Hospital, a 1,300-bed university hospital of the Faculty of Medicine Ramathibodi Hospital, Mahidol University located in Bangkok and providing tertiary care, the amount and cost of use of BPs should be monitored. This study was therefore conducted to investigate (i) the percentage of prescribing BPs concordant to Thai osteoporosis foundation (TOPF) 2010 guideline, (ii) the cause of prescribing BPs non-concordant to the TOPF 2010 guideline, (iii) the prevalence of osteoporotic fracture, (iv) the factors related to osteoporotic fractures, and (v) the loss of medication cost determined from group of patients who received BPs non-concordant to TOPF 2010 guidelines.

\section{MATERIALS AND METHODS}

\subsection{Study design}

This was a nested case-control study.

\subsection{Study subjects}

On reviewing data from electronic medical record, there were 12,000 postmenopausal women and men aged $\geq 50$ years who received BPs in Ramathibodi Hospital from 2012 to 2016. Population was further sampled in a systematic random method to 6,000 patients. The occurrence of osteoporotic fracture in the sample was then individually reviewed backward to the year of their starting BPs. The majority of cases were observed to start BPs in 2012. Therefore, all patients of January - December 2012 were enrolled in the study according to inclusion and exclusion criteria and the number of sample was eventually 1,000 meanwhile by the Yamane equation ${ }^{18}$, the calculated sample size would be 387 patients.

\subsubsection{Inclusion criteria}

1) They were postmenopausal women or men and

2) They were $\geq 50$ years old 


\subsubsection{Exclusion criteria}

1) They received BPs less than 6 months, or

2) They were contraindicated for BPs, i.e., having glomerular filtration rate (GFR) less than $30 \mathrm{~mL} / \mathrm{min}$ (in case of oral form of BPs) or $35 \mathrm{~mL} / \mathrm{min}$ (in case of injection form of BPs).

\subsection{Study procedure}

Study patients were categorized according to the BPs they received whether the prescribed medications were concordant to the criteria of the TOPF 2010 guideline or not. Two groups of study patients were classified; (1) patients who were treated for osteoporosis concordant to the guideline (1.1) patients who had previous hip or vertebral fractures or $\mathrm{T}$ scores $\leq-2.5$ at the femoral neck, total hip or lumbar spine, (1.2) Tscore of $\geq-2.5$ but $<-1$ plus the presence of 1 or more criteria (FRAX score for hip fracture $\geq 3 \%$ or other major osteoporotic fractures $\geq 20 \%$, lowtrauma fracture after aged $\geq 40$ years, prolonged use of glucocorticoids, having a secondary osteoporosis such as rheumatoid arthritis, thyroid disorder or having 2 clinical risk factors of women aged $\geq 65$ years or men aged $\geq 70$ years and BMI $<19 \mathrm{~kg} / \mathrm{m} 2$ ). (2) patients who received BPs that did not follow the above criteria was the non-concordant group. Data of each patient was retrieved from electronic medical record, collected and analyzed. In case of patients who had fracture after BPs, the incidence was confirmed by orthopedist whether it was osteoporotic fracture or not.

\subsection{Data collection}

Data were collected from electronic medical record, as the followings:

\subsubsection{Demographic data}

Table 1. Demographic data of study patients.
Patients' information including age, gender, body mass index (BMI), family history and smoking and drinking behaviors were collected.

\subsubsection{Medical data}

Medical data including name of BPs, underlying diseases, and history of bone fracture were collected.

\subsubsection{Laboratory data}

Laboratory data including BMD, GFR, and FRAX® score were collected.

\subsection{Statistical Analysis}

Descriptive statistics were used in analyzing all variables. The Mann Whitney U test, chi-square or Fisher's exact probability test was used to compare variables of different values between groups of patients receiving BPs concordant and non-concordant to TOPF 2010 guideline, and Pvalue of less than 0.05 was considered statistically significant. Factors related to osteoporotic fracture were analyzed by univariate or multivariate logistic regression if one or multiple factors were involved.

\section{RESULTS}

\subsection{Demographic data of study populations}

In total 1,000 patients were recruited. Table 1 presented demographic data of study patients. The average age of patients was 67.6 years and most patients were in the age range between 60 to 69 years. Populations were predominantly female $(95.7 \%)$ and the average BMI is $23.6 \mathrm{~kg} / \mathrm{m}^{2}$. Family history (parental history of hip fracture), smoking and drinking behaviors were not collected although it was planned in the study procedure, due to data missing in the electronic data.

\begin{tabular}{lc}
\hline \multicolumn{1}{c}{ Variables } & $\begin{array}{c}\text { Number of patients (\%) } \\
(\mathbf{N = 1 , 0 0 0})\end{array}$ \\
\hline Age, mean \pm SD (year) & $67.6 \pm 9.3$ \\
$50-59$ years & $210(21.0)$ \\
$60-69$ years & $389(38.9)$ \\
$70-79$ years & $284(28.4)$ \\
$80-89$ years & $108(10.8)$ \\
$\geq 90$ years & $9(0.9)$ \\
Gender & $43(4.3)$ \\
Male & $957(95.7)$ \\
Female & $23.6 \pm 3.9$ \\
BMI $\left(\mathrm{kg} / \mathrm{m}^{2}\right)$, mean \pm SD &
\end{tabular}




\subsection{Baseline characteristics}

Table 2 presented baseline characteristic data of study patients. Two-thirds of patients received BPs from Gynecologists and Orthopedists and $1 / 3$ of patients received BPs from physicians of Department of Medicine. BMD was measured in 92.7\% of study patients. From the BMD value, around $52 \%$ were classified as osteoporosis,
$35.5 \%$ were low bone mass or osteopenia, $10 \%$ were severe osteoporosis and $2 \%$ were normal. FRAX ${ }^{\circledR}$ score was assessed in $84.4 \%$ of patients, and the result showed $35.2 \%$ of patients with 10 -year probabilities of hip fracture $\geq 3 \%$ and $10.8 \%$ of patients with 10 -year probability of other major osteoporotic fractures $\geq 20 \%$. Majority of patients $(82.8 \%)$ had no history of bone fracture before 2012 .

Table 2. Baseline characteristics.

\begin{tabular}{|c|c|}
\hline Variables & $\begin{array}{c}\text { Number of patients }(\%) \\
(\mathrm{N}=1,000)\end{array}$ \\
\hline \multicolumn{2}{|l|}{ Specialty clinic being visited by study patients } \\
\hline Gynecology & $436(43.6)$ \\
\hline Orthopedic & $349(34.9)$ \\
\hline Medicine & $215(21.5)$ \\
\hline \multicolumn{2}{|l|}{ BMD measurement } \\
\hline Yes & $927(92.7)$ \\
\hline No & $73(7.3)$ \\
\hline \multicolumn{2}{|l|}{ WHO classification of osteoporosis, $\mathrm{N}=927$} \\
\hline Normal & $25(2.7)$ \\
\hline Low bone mass (osteopenia) & $329(35.5)$ \\
\hline Osteoporosis & $479(51.7)$ \\
\hline Severe osteoporosis & $94(10.1)$ \\
\hline \multicolumn{2}{|l|}{ FRAX® score assessment, $\mathrm{N}=927$} \\
\hline Yes (Available) & $782(84.4)$ \\
\hline No (Not-available) & $145(15.6)$ \\
\hline \multicolumn{2}{|c|}{ FRAX® ${ }^{\circledR} 10$-year probability of hip fracture, $N=927$} \\
\hline$\geq 3 \%$ & $326(35.2)$ \\
\hline$<3 \%$ & $456(49.2)$ \\
\hline Missing data & $145(15.6)$ \\
\hline \multicolumn{2}{|c|}{ FRAX $® 10$-year probability of other major osteoporotic fractures, $N=927$} \\
\hline$\geq 20 \%$ & $100(10.8)$ \\
\hline$<20 \%$ & $682(73.6)$ \\
\hline Missing data & $145(15.6)$ \\
\hline \multicolumn{2}{|l|}{ History of fracture before $2012, \mathrm{~N}=1000$} \\
\hline Yes & $172(17.2)$ \\
\hline No & $828(82.8)$ \\
\hline
\end{tabular}

$B M D=$ Bone mineral density, $B M I=$ Body mass index

\subsection{Bisphosphonate therapy}

Around $80 \%$ of study patients received oral BPs (Table 3). Risedronate was prescribed much more than Alendronate, around 2:1.
Almost 800 patients $(78.4 \%)$ received BPs concordant to the TOPF 2010 guideline and 216 patients $(21.6 \%)$ did not.

Table 3. Distribution of patients receiving bisphosphonate therapy.

\begin{tabular}{|c|c|}
\hline Variables & $\begin{array}{c}\text { Number of patients }(\%) \\
\mathrm{N}=\mathbf{1 , 0 0 0} \\
\end{array}$ \\
\hline \multicolumn{2}{|l|}{ Type of BPs } \\
\hline Oral form & $826(82.6)$ \\
\hline Alendronate & $206(20.6)$ \\
\hline Alendronate plus cholecalciferol & $87(8.7)$ \\
\hline Risedronate & $533(53.3)$ \\
\hline Injections (Zoledronic acid) & $174(17.4)$ \\
\hline \multicolumn{2}{|c|}{ BPs concordance to the TOPF2010 guideline } \\
\hline Concordance & $784(78.4)$ \\
\hline Non-concordance & $216(21.6)$ \\
\hline
\end{tabular}




\subsection{Cause of prescribing BPs non-concordant to the TOPF 2010 guideline}

Among those who received BPs nonconcordant to the TOPF 2010 guideline, 4 groups were classified according to BMD testing and history of bone fracture (Table 4). The first rank was found in 104 patients (48.1\%). They had low bone mass (osteopenia) but no clinical risk factor. Thus the cause of prescribing BPs to this group could be due to data showing osteopenia.
The second rank was found in 53 patients (24.5\%), and they had neither previous BMD testing nor history of bone fracture. This group thus received BPs without determined reason.

The third rank was found in 42 patients $(19.5 \%)$. They were women age $\geq 65$ years and had osteopenia. Thus the cause of prescribing BPs to this group could be due to data showing osteopenia with one clinical risk factor.

The rest were 17 patients $(7.9 \%)$ with normal in BMD testing. This group thus received BPs because they had BMD testing.

Table 4. Analysis cause of prescribing BPs non-concordant to the TOPF 2010 guideline.

\begin{tabular}{lc}
\hline \multicolumn{1}{c}{ Cause of prescribing BPs not-according to guideline } & $\begin{array}{c}\text { Number of patients (\%) } \\
(\mathbf{N = 2 1 6})\end{array}$ \\
\hline No previous BMD measurement and no history of fracture & $53(24.5)$ \\
BMD measurement (Normal) & $17(7.9)$ \\
BMD measurement (Low bone mass (osteopenia)) with only one clinical risk & $42(19.5)$ \\
factor & $42(19.5)$ \\
Women age $\geq 65$ years & 0 \\
BMI <19 $\left(\mathrm{kg} / \mathrm{m}^{2}\right)$ & \\
BMD measurement (Low bone mass (osteopenia) without clinical risk factor & $104(48.1)$ \\
\hline
\end{tabular}
$B M D=$ Bone mineral density, $B M I=$ Body mass index

\subsection{Prevalence of osteoporotic fractures}

Prevalence of osteoporotic fractures was $2.9 \%$. This composed of 17 patients $(1.7 \%)$ with major fractures and 12 patients $(1.2 \%)$ with non-major fractures (Table 5).
Major fractures were classified as 7 patients $(0.7 \%)$ with hip fracture and 10 patients $(1.0 \%)$ with spine fracture. Furthermore, non-major fractures were divided into upper extremity fractures and lower extremity fractures, 6 patients each $(0.6 \%)$.

Table 5. Prevalence of osteoporotic fractures of population in this study.

\begin{tabular}{lc}
\hline \multicolumn{1}{c}{ Prevalence of osteoporotic fracture after BPs initiation } & $\begin{array}{c}\text { Number of patients (\%) } \\
(\mathbf{N = 1 , 0 0 0 )}\end{array}$ \\
\hline Overall fracture & $29(2.9)$ \\
Major fracture & $17(1.7)$ \\
Hip fracture & $7(0.7)$ \\
Spine fracture & $10(1.0)$ \\
Non-major fractures & $12(1.2)$ \\
Upper extremity fracture (humerus and distal end radius bone) & $6(0.6)$ \\
Lower extremity fracture (ankle, coccyx, metartasal and pelvic bone) & $6(0.6)$ \\
\hline
\end{tabular}

Age and BMI of patients who received BPs concordant and non-concordant to the TOPF 2010 guideline ( $\mathrm{N}=784$ and 216 , respectively) were significantly different, $(\mathrm{P}=<0.0001$ and $\mathrm{P}=<0.0001$, respectively) as shown in Table 6 . Type of BPs taken between 2 groups showed significant difference in the oral form of alendronate and alendronate plus cholecalciferol and risedronate $(\mathrm{P}=0.0007)$. Number of patients who got or did not get BMD measurement, WHO classification, FRAX® score tool, FRAX® 10year probability of hip fracture and FRAX ${ }^{\circledR} 10$ year probability of other major osteoporotic fractures were significantly different between 2 groups $(\mathrm{P}=<0.0001)$. Others factors were not significantly different.

Prevalence of osteoporotic fracture showed no significant difference in overall fractures between patients who received BPs concordant to and non-concordant to the TOPF 2010 guideline $(2.6 \%$ versus $4.2 \%$; Odds ratio $=0.602 ; \quad 95 \% \mathrm{Cl}=0.270-1.342 ; \quad \mathrm{P}=0.306)$. Ratio of prevalence of major fractures over minor fractures showed no significant difference between 2 groups (1.6\%:1.0\% versus $2.3 \%: 1.9 \% ; \mathrm{P}=1.000)$. Similarly, type of major 
fractures (hip:spine) and type of minor fractures (upper extremity:lower extremity) were not significantly different between 2 groups
$(0.8 \%: 0.8 \%$ versus $0.4 \%: 1.9 \% ; \mathrm{P}=0.338$ and $0.6 \%: 0.4 \%$ versus $1.5 \%: 0.4 \% ; \quad \mathrm{P}=1.000$, respectively).

Table 6. Comparison between patients who received BPs concordance to and non-concordant to the TOPF 2010 guideline.

\begin{tabular}{|c|c|c|c|}
\hline \multirow[t]{2}{*}{ Variables } & \multicolumn{3}{|c|}{ Number of patients who received BPs therapy (\%) } \\
\hline & $\begin{array}{l}\text { Concordance } \\
\mathrm{N}=784\end{array}$ & Non-concordance $\mathrm{N}=216$ & P-value \\
\hline $\begin{array}{l}\text { Age (year) at the beginning of BPs, } \\
\text { median (IQR) }\end{array}$ & $68(61-75)$ & $64(58-71)$ & $<0.0001^{*}$ \\
\hline \multicolumn{4}{|l|}{ Gender } \\
\hline Male & $32(4.1)$ & $11(5.1)$ & $0.646 * *$ \\
\hline Female & $752(95.9)$ & $205(94.9)$ & \\
\hline BMI $\left(\mathrm{kg} / \mathrm{m}^{2}\right)$, median (IQR) & $22.83(20.57-25.63)$ & $24.19(22.10-27.10)$ & $<0.0001 *$ \\
\hline$<19$ & $83(10)$ & $7(3)$ & \\
\hline$\geq 19$ & $701(90)$ & $209(97)$ & \\
\hline \multicolumn{4}{|l|}{ Type of BPs } \\
\hline Oral form: Injections & $643(82.0): 141(18.0)$ & $183(84.7): 33(15.3)$ & $0.353 * *$ \\
\hline $\begin{array}{l}\text { Type of oral form } \\
\text { Alendronate and } \\
\text { Alendronate plus } \\
\text { cholecalciferol: } \\
\text { Risedronate }\end{array}$ & $248(38.6): 395(61.4)$ & $45(24.6): 138(75.4)$ & $0.0007 * *$ \\
\hline \multicolumn{4}{|l|}{ BMD measurement } \\
\hline $\begin{array}{l}\text { Yes } \\
\text { No }\end{array}$ & $\begin{array}{l}764(97.4) \\
20(2.6)\end{array}$ & $\begin{array}{c}163(75.5) \\
53(24.5)\end{array}$ & $<0.0001 * *$ \\
\hline \multicolumn{4}{|l|}{ WHO classification of osteoporosis } \\
\hline $\begin{array}{l}\text { Low bone mass } \\
\text { (osteopenia) }\end{array}$ & $\begin{array}{c}8(1.0) \\
183(24.0)\end{array}$ & $\begin{array}{c}17(10.4) \\
146(89.6)\end{array}$ & $<0.0001 * * *$ \\
\hline \multicolumn{4}{|l|}{ Osteoporosis } \\
\hline Severe osteoporosis & $\begin{array}{l}479(62.7) \\
94(12.3)\end{array}$ & $\begin{array}{l}0(0) \\
0(0)\end{array}$ & \\
\hline \multicolumn{4}{|l|}{ FRAX® score } \\
\hline $\begin{array}{l}\text { Yes } \\
\text { No }\end{array}$ & $\begin{array}{l}764(97) \\
20(3)\end{array}$ & $\begin{array}{l}163(75) \\
53(25)\end{array}$ & $<0.0001 * *$ \\
\hline \multicolumn{4}{|l|}{$\begin{array}{l}\text { FRAX® 10-year probability of hip } \\
\text { fracture }\end{array}$} \\
\hline$\geq 3 \%$ & $325(42.5)$ & $0(0)$ & $<0.0001 * *$ \\
\hline$<3 \%$ & $312(40.8)$ & $145(89.0)$ & \\
\hline Missing data & 127 (16.7) & 18 (11.0) & \\
\hline \multicolumn{4}{|l|}{$\begin{array}{l}\text { FRAX® } 10 \text {-year probability of other } \\
\text { major osteoporotic fractures } \\
\geq 20 \%\end{array}$} \\
\hline$<20 \%$ & $100(13.1)$ & $0(0)$ & $<0.0001 * *$ \\
\hline Missing data & $\begin{array}{l}537(70.3) \\
127(16.6)\end{array}$ & $\begin{array}{c}145(89.0) \\
18(11.0)\end{array}$ & \\
\hline \multicolumn{4}{|l|}{$\begin{array}{l}\text { Prevalence of osteoporotic fracture } \\
\text { after BPs initiation }\end{array}$} \\
\hline Overall fracture & $20(2.6)$ & $9(4.2)$ & $\begin{aligned} \mathrm{OR} & =0.602 \\
95 \% \mathrm{Cl} & =0.270- \\
1.342 ; \mathrm{P} & =0.306 * *\end{aligned}$ \\
\hline $\begin{array}{l}\text { Major : Minor } \\
\text { Type of major fracture }\end{array}$ & $12(1.6): 8(1.0)$ & $5(2.3): 4(1.9)$ & $1.000 * * *$ \\
\hline $\begin{array}{l}\text { Hip : Spine } \\
\text { Type of minor fracture }\end{array}$ & $6(0.8): 6(0.8)$ & $1(0.4): 4(1.9)$ & $0.338 * * *$ \\
\hline Upper : Lower & $5(0.6): 3(0.4)$ & $3(1.5): 1(0.4)$ & $1.000 * * *$ \\
\hline $\begin{array}{l}\text { IQR= Interquartile range } \\
B M I=\text { Body mass index } \\
B P s=\text { Bisphosphonate } \\
B M D=\text { Bone mineral density } \\
* \text { Mann Whitney } U \text { test } \\
* * \text { Chi-square test } \\
* * * \text { Fisher's exact test }\end{array}$ & & & \\
\hline
\end{tabular}




\subsection{Factors related to osteoporotic fracture}

Table 7 presented univariate logistic regression analysis of factors which were related to osteoporotic fracture. Age showed significant relationship to osteoporotic fracture
(Odds ratio $=1.0658 ; 95 \% \mathrm{Cl}=1.0248-1.1084$; $\mathrm{P}=0.0015)$. On the other hand, gender, prescribing BPs non-concordant to TOPF 2010 guideline, administration routes of BPs (injection form: oral form), GFR, BMI and comorbid conditions were not.

Table 7. Factors related to osteoporotic fracture by logistic regression analysis.

\begin{tabular}{lccc}
\hline \multicolumn{1}{c}{ Factors } & Odds ratio & 95\% CI & P-value \\
\hline Age (men $\geq 70$ plus women $\geq$ 65 years)* & 1.0658 & $1.0248-1.1084$ & 0.0015 \\
Gender ( men : women) & 1.6802 & $0.3863-7.3077$ & 0.4890 \\
BPs concordance to TOPF guideline (yes : no) & 0.6021 & $0.2701-1.3421$ & 0.2148 \\
Administration routes of BPs (injection form : oral form) & 0.7539 & $0.2590-2.1943$ & 0.6043 \\
GFR** & 0.9866 & $0.9671-1.0064$ & 0.1843 \\
BMI (BMI $<19:$ BMI $\geq 19$ ) & 0.4460 & $0.1460-1.3650$ & 0.1470 \\
Comorbid conditions*** & 1.4930 & $0.1530-14.5230$ & 0.7280 \\
\hline
\end{tabular}

*Age was compared between groups of patients (men $\geq 70$ plus women $\geq 65$ years versus men $<70$ plus women $<65$ years). $B P s=$ Bisphosphonate, $G F R=$ Glomerular filtration rate, $B M I=$ Body mass index

**GFR was compared by using continuous data.

*** Comorbid conditions were collected only in osteopenia group which was classified the patients who had rheumatoid arthritis or thyroid disorder.

\subsection{Loss of medication cost due to prescribing BPs non-concordant to the TOPF 2010 guideline}

From 216 cases who received BPs nonconcordant to the guideline, Alendronate plus cholecalciferol was consumed by 9 patients, Alendronate was consumed by 36 patients, Risedronate was consumed by 138 patients, and Zoledronic acid was consumed by 33 patients
(Table 8). On assumption that each BPs was used along 52 weeks, Alendronate plus cholecalciferol and Alendronate cost were estimated to 18,512 Thai Baht (THB)/person/year, Risedronate 20,748 THB/person/year and Zoledronic acid 17,128 $\mathrm{THB} /$ person/year. The total cost of medications used by 216 patients would be 4,261,488 THB/year (average annual treatment expenditure per capita was 19,729 THB). This cost was recognized to be loss in health economics.

Table 8. Loss of medication cost observed in patients who received BPs non-concordant to the TOPF 2010 guidelines. (The reference price of medications based on drug prices in Ramathibodi Hospital in 2012)

\begin{tabular}{lcccc}
\hline \multicolumn{1}{c}{ Type of BPs } & $\begin{array}{c}\text { Price } \\
\text { (Baht)/per 1 } \\
\text { dose }\end{array}$ & $\begin{array}{c}\text { Price (Baht)/per } \\
\text { year }\end{array}$ & $\begin{array}{c}\text { Number of } \\
\text { patients }\end{array}$ & $\begin{array}{c}\text { Total/per year } \\
\text { (Baht) }\end{array}$ \\
\hline Alendronate plus cholecalciferol & 356 & 18,512 & 9 & 166,608 \\
Alendronate & 356 & 18,512 & 36 & 666,432 \\
Risedronate & 399 & 20,748 & 138 & $2,863,224$ \\
Zoledronic acid & 17,128 & 17,128 & 33 & 565,224 \\
& & & Total 4,261,488 Baht \\
Average annual treatment expenditure per capita was 19,729 THB & & \\
\hline
\end{tabular}

\section{DISCUSSION}

The nested case-control study was conducted to determine the percentage of BPs used for osteoporosis that was concordant to the TOPF 2010 guideline at Ramathibodi Hospital during January-December 2012. The results in the present study provided evidence that the number of BPs concordant and non-concordant to the TOPF 2010 guideline were 784 patients (78.4\%) and 216 patients (21.6\%), respectively. The result was similar to the study of Kungsworn et al. who reviewed the prescribing of BPs (alendronate and risedronate) in health promoting hospital, and the sixth Regional Health Promotion Center. They found that almost all patients received BPs that were rational ${ }^{19}$. Similarly, the study of Soontornpas et al. mentioned that patients around $60 \%$ had rational use of anti-osteoporosis drugs at a university hospital $^{20}$.

There were 216 patients receiving BPs non-concordant to the TOPF 2010 guideline. Most of them, 104 patients (48.1\%) had low BMD which was recognized as osteopenia without clinical risk factor. This non-concordance might be 
due to the fact that most of study patients were elderly, and came to hospital because of bone disease problem. Physician ordered BMD testing and result later revealed low bone mass or osteopenia status. In spite of non-supporting BMD data, BPs was started to these elderly patients to prevent bone fracture and to help BMD not turnover to osteoporosis. Soontornpas et al. reported the higher inappropriate antiosteoporotic drug use in a university hospital as compared to our study. They found $60 \%$ inappropriateness in patients with BMD T-score $\geq-2.5$ and no clinical risk factor and $20 \%$ inappropriateness in patient aged $<65$ years and BMD T-score <-2.5 and having clinical risk factor less than 2 factors. This difference might be due to the different inclusion/exclusion criteria, i.e., the patient started to use antiosteoporotic drug when patient had hip or vertebral fracture from low-trauma or patient aged $\geq 65$ years and had BMD T-score $<-2.5$ or patient aged $<65$ years and had BMD T-score <2.5 plus 2 clinical risk factors ${ }^{20}$.

Prevalence of overall osteoporotic fracture of $2.9 \%$ was found in this study meanwhile the prevalence in the group of concordance to non-concordance was in the ratio $2.6 \%: 4.2 \%$. Our study showed that the increasing age tends to have osteoporotic fracture. This result was similar to the study of Krege JH et al., indicated that fracture risk increased in both men and women with increasing age ${ }^{21}$ and the study of Cranney A et al., mentioned that overall fracture rates were significantly higher among women at least 65 years of age than among younger women 50-64 years of age $(21.6$ [95\% CI 19.7-23.4] versus 8.6 [95\% CI 7.5-9.7] per 1000 person-years) ${ }^{22}$. Loss of medication cost in the group of patients who received BPs nonconcordant to the TOPF 2010 guideline was $4,261,488 \mathrm{THB} /$ year or $19,729 \mathrm{THB} /$ person/year. This high amount of money should be considered. Nearly half of non-concordant group were patients who had low bone mass status without clinical risk factors, but they still received BPs. This led to economic burden and unnecessary drug use. It would be more beneficial if clinical risk factors must be added to BMD measurement in low bone mass patients before prescribing BPs. The present study also showed that BPs were used without BMD measurement in approximately $25 \%$ of nonconcordant group. This added-on economic burden and unnecessary drug use. Policy-maker should realize this result and adopt guideline that BMD measurement should be performed before using BPs in all cases especially patient age $\geq 70$ years in men and $\geq 65$ years in women.

This study had limitations which have to be pointed out. The study was retrospective, and some missing data were un-avoidable. Data of smoking and drinking behaviors were not included in all electronic medical records. This led to inability to specify whether smoking and drinking behaviors were cause of non-concordant using or not.

\section{CONCLUSIONS}

Higher percentage of patients received BPs concordant to the TOPF 2010 guideline than patients who did not (78.4\%:21.6\% or 3.6 times). The first rank cause of using BPs non-concordant to the guideline was being low bone mass without clinical risk factors. The prevalence of osteoporotic fractures in both groups was not significantly different and there was $2.9 \%$ of all study patients. Age (men $\geq 70$ and women $\geq 65$ years) was related to osteoporotic fracture. In addition, loss of medication cost in nonconcordant group was 4,261,488 THB/year or 19,729 THB/person/year. In conclusion, use of BPs in this study was mostly rational.

\section{ACKNOWLEDGEMENTS}

We would like to thank the Faculty of Pharmacy, Mahidol University, Department of Orthopedics, Ramathibodi Hospital and Department of Clinical Pharmacy, Ramathibodi Hospital for the support in collecting and analyzing data for the study.

\section{Conflict of interest}

None to declare.

\section{Funding}

None to declare.

\section{Ethics approval and consent to participate}

Ethical approval was obtained from Faculty of Medicines Ramathibodi Hospital, Mahidol University's ethics committee, according to certificate ID 11-60-02, February 21th, 2018.

\section{Article info:}

Received September 8, 2019

Received in revised form April 12, 2020

Accepted April 24, 2020 


\section{REFERENCES}

1. Zhou J, Ma X, Wang T, Zhai S. Comparative efficacy of bisphosphonate in short-term fracture prevention for primary osteoporosis: a systematic review with network meta-analyses. Osteoporos Int. 2016;27:3289-300.

2. Melton LJ, Chrischilles EA, Cooper C, Lane AW, Riggs BL. Perspective. How many women have osteoporosis? J Bone Miner Res. 1992;7:1005-10.

3. Johnell O, Kanis JA. An estimate of the worldwide prevalence and disability associated with osteoporotic fractures. Osteoporos Int. 2006;17:1726-33.

4. Iolascon G, Sirico F, Ferrante A, Gimigliano R, Gimigliano F. Risedronate's efficacy: from randomized clinical trials to real clinical practice. Clin Cases Miner Bone Metab. 2010;7:19-22.

5. Pattanaungkul S. A rational approach in the management of osteoporosis. RTA Med J. 2006;59:93-115.

6. Cosman F, Beur SJ, Leboff MS, Lewiecki EM, Tanner B, Randell S, et al. Clinician's guide to prevention and treatment of osteoporosis. Osteoporos Int. 2014;25:2359-81.

7. Taepongsorat L. Osteoporosis: epidemiology, causes, diagnosis, treatments. J Sci Technol MSU. 2014;33(5): 526-36.

8. Orimo H, Nakamura T, Hosoi T, Iki M, Uenishi K, Endo N, et al. Japanese 2011 guidelines for prevention and treatment of osteoporosis - executive summary. Arch Osteoporos. 2012;7:3-20.

9. Malazy OT, Salari P, Khashayar P, Larijaril B. New horizons in treatment of osteoporosis. Daru J Pharm Sci. 2017;25(2):1-16.

10. Black DM, Rosen CJ. Postmenopausal osteoporosis. N Eng J Med. 2016;374(3):254-62.

11. Khan A and Fortier M. Osteoporosis in menopause. J Obstet Gynaecol Can. 2014;36(9 eSuppl C):S1-15.

12. Bubbear JS. Atypical femur fracture in patients treated with bisphosphonates: identification, management, and prevention. Rambam Maimonides Med J. 2016;7(4):1-9.

13. Mcclung M, Harris ST, Miller PD, Bauer DC, Davison KS, Dian L, et al. Controversies in osteoporosis management: concerns about bisphosphonates and when are "drug holidays" required? Clin Obstet Gynecol. 2013;56:743-8

14. Adler RA. Bisphosphonates and atypical femoral fractures. Curr Opin Endocrinol Diabetes Obes. 2016;23:430-4.

15. Fraser LA, Vogt KN, Adachi JD, Thabane L. Fracture risk associated with discontinuation of bisphosphonates after 5 years of therapy in patients with primary osteoporosis: a systematic review and meta-analysis. Ther Clin Risk Manag. 2011;7:157-66.

16. Saita Y, Ishijima M, Kaneko K. Atypical femoral fractures and bisphosphonate use: current evidence and clinical implications. Ther Adv Chronic Dis. 2015;6:185-93

17. Chaiyasong $\mathrm{S}$, Rattanachotphanit $\mathrm{T}$, Waleekhachonloet O, Sitthithanyakit. Cost-effectiveness of alendronate and risedronate for primary prevention of fracture in postmenopausal women. IJPS. 2013;9:24-36.

18. Faculty of Medicine Siriraj Hospital knowledge management. Sample size in quantitative review [Internet]. 2011 [cited 2020 Apr 10]. Available from: http://www1.si.mahidol.ac.th/km/sites/default/files/sa mple_size_0.pdf.

19. Kungsworn P, Waleekhajornlert O, Limwattananon C, Sakolchai S. Drug use review of bisphosphonates and raloxifene for osteoporosis treatment at the Postmenopausal Clinic, Health Promoting Hospital, Regional Health Promotion Center 6. IJPS 2008;4:46-56.

20. Soontornpas R, Soontornpas C. Assessment of rationale use of anti-osteoporosis drugs at a university hospital. IJPS. 2018;14(2):47-55

21. Krege JH, Wan X, Lentle BC, Berger C, Langsetmo L, Adachi JD, et al. Fracture risk prediction: importance of age, BMD and spine fracture status. Bonekey Rep. 2013;2:1-7.

22. Cranney A, Jamal SA, Tsang JF, Josse RG, Leslie. Low bone mineral density and fracture burden in postmenopausal women. CMAJ. 2007;177:575-80. 